\title{
Percepções de alunos de Letras-inglês para as potencialidades pedagógicas das tecnologias digitais ${ }^{1}$
}

\author{
Marcus de Souza Araújo² \\ Faculdade de Letras Estrangeiras Modernas/Programa de Pós-Graduação Criatividade e Inovação em \\ Metodologias do Ensino Superior, Universidade Federal do Pará, Belém, PA, Brasil.
}

Resumo: O objetivo deste artigo é apresentar a percepção de dois alunos do curso de Letras-Inglês sobre a aprendizagem com o uso das tecnologias digitais. Os dados foram gerados em uma disciplina curricular acadêmica específica sobre tecnologias deste curso de uma universidade federal do norte do país. A presente pesquisa se constitui como um estudo de caso qualitativo (STAKE, 1995; YIN, 2015) e utiliza como instrumentos de pesquisa dois questionários, uma entrevista e relatos reflexivos. O referencial teórico baseia-se nos usos das tecnologias digitais (BATES, 2016; ECHEVERRÍA, 2015; PISCHETOLA, 2016; entre outros) e nos conceitos de formação reflexiva de professores (LIBERALI, 2010; NÓVOA, 1995, 2014; RAMOS, 2015; SCHÖN, 1983, 2000; entre outros). Os resultados apontam que uma disciplina acadêmica específica sobre tecnologias tem papel relevante no curso de formação inicial de professores de inglês, pois além de mostrar a diversidade de aprendizagem com diferentes interfaces tecnológicas digitais, possibilita, também, que o futuro professor venha a refletir a respeito das potencialidades e da apropriação dessas tecnologias para fins pedagógicos.

Palavras-chave: Tecnologias digitais; Formação de professores; Aprendizagem de inglês.

Title: Students' perceptions of an English-Language Undergraduate Teacher Program for Digital Technologies Pedagogical Potential

Abstract: The purpose of this study is to present two students' perceptions of an English-language teaching undergraduate program about learning with the use of digital technologies. The research data were gathered in a curricular subject on technologies on this undergraduate program at a federal university in the north of Brazil. This study is considered a qualitative case study (STAKE, 1995; YIN, 2015) and the research instruments used were two questionnaires, an interview, and reflective reports. The theoretical bases are based on digital technologies (BATES, 2016; ECHEVERRÍA, 2015; PISCHETOLA, 2016; among others) and the concepts of reflective teacher education (LIBERALI, 2010; NÓVOA, 1995, 2014; RAMOS, 2015; SCHÖN, 1983, 2000; among others). The results point out that a specific academic subject on technologies plays a relevant role in English-language teaching undergraduate programs, since not only does it provide learning diversity with different

\footnotetext{
${ }^{1}$ Este artigo é um micro recorte da tese de doutorado intitulada "Tecnologias Digitais da Informação e Comunicação para Fins Educacionais na Formação Inicial de Professores de Inglês" (ARAÚJO, 2017), cujos dados da pesquisa foram aprovados pelo Comitê de Ética em Pesquisa da PUC-SP no dia 9 de junho de 2015. N $^{\circ}$ do Parecer: 1.098.714.

2 Doutor em Linguistica Aplicada e Estudos da Linguagem (PUC-SP). Universidade Federal do Pará. Orcid: https://orcid.org/0000-0001-5403-0879
}

E-mail: marcusaraujo@interconect.com.br 
digital technological interfaces. Otherwise, it also allows the teacher-to-be to reflect upon the potential and appropriation of these technologies for teaching purposes.

Keywords: Digital technologies; Teacher education; English-learning.

\section{Introdução}

Os cursos de formação de professores são área específica do conhecimento acadêmico que precisam ser direcionados para uma prática reflexiva da docência, para apoiar o futuro professor a aprender e a desenvolver uma competência profissional especializada. Sobre a prática reflexiva, considero-a não um processo psicológico individual, independente do conteúdo e do contexto do professor-aprendiz (GÓMEZ, 1995; NÓVOA, 1995; RAMOS, 2015), porém "uma ação consciente realizada pelo professor, que busca compreender o seu próprio pensamento, sua ação e suas consequências" (LIBERALI, 2010, p. 25). Logo, esses cursos precisam ser pensados individualmente, de acordo com as necessidades e os interesses de cada região e de cada localidade brasileira, se considerarmos a dimensão territorial, quase transcontinental de nosso país, com currículos e com metodologias apropriados para cada realidade.

Imbernón (2016), assim como García (1995) e Nóvoa (1995, 2014), preocupando-se, também, com essa questão, ressalta que os cursos de formação inicial de professores apresentam uma visão prescritiva da profissão, na maioria das vezes, e deixam, em segundo plano, as práticas reflexivas necessárias, para o futuro professor entender melhor seu papel, em seu futuro contexto de atuação. García (1995) usa o termo indagação-reflexão para a prática consciente das atividades desenvolvidas pelo professor em seu contexto de ensino, além de analisar as causas e as consequências de sua conduta, superando os limites dos muros da escola.

Caminhando nessa direção, Ramos (2015) parte em defesa do professor em formação inicial em obter consciência de seu contexto de atuação, das influências e das restrições impostas por conhecimentos (pré)estabelecidos, saber interligar, epistemologicamente, os conhecimentos teóricos e as práticas reflexivas, além de apresentar controle sobre o direcionamento de suas ações, para que, dessa forma, possam ser agentes reflexivos dos próprios processos de construção e reconstrução de suas futuras práticas pedagógicas.

Convém lembrar que nessa seara de convergência com a formação do professor, as Tecnologias Digitais da Informação e Comunicação (TDIC) evoluem em ritmo acelerado e transformam a maneira de pensar e de agir das pessoas na Sociedade da Informação, seja no lazer ou no trabalho, sejam nas tarefas cotidianas ou na educação. É claro que, apesar de viverem na era digital, grande parte dos jovens e dos adultos ainda não desenvolveram habilidades necessárias para atuarem em um mundo mediado pelas TDIC. O que faz incluir, também, a área da Educação, que demanda práticas didáticas planejadas com a integração sistemática das TDIC no ensino e na aprendizagem, como forma de se criar espaços na escola 
brasileira (também nas universidades e nas faculdades) para possíveis mudanças pedagógicas e tecnológicas, conscientemente.

Entendo, assim, ser necessário o uso consciente e regular das TDIC pelos professores em suas disciplinas e seus contextos específicos, com currículos flexíveis, que favoreçam o uso efetivo e a integração das tecnologias, tanto no contexto escolar, quanto no acadêmico, para transformar a educação no contexto brasileiro, pois as TDIC estão cada vez mais presentes, e sem volta, no dia a dia. Por esse motivo, a necessidade de cursos de formação para instrumentalizar o professor a aprender a operacionalizar, de maneira reflexiva, funcional e pedagogicamente as TDIC em suas práticas educacionais.

Nesse contexto de integração das TDIC com a formação reflexiva do professor de inglês, tenho por objetivo, neste artigo, apresentar a percepção de dois alunos do curso de Letras-Inglês acerca do uso das TDIC para a aprendizagem de língua inglesa a partir da disciplina curricular acadêmica "Tecnologias no ensino/aprendizagem de língua estrangeira", que será mais bem descrita adiante.

Para desenvolver minha proposta, organizo este artigo em cinco seções, além desta introdução. Apresento, inicialmente, o arcabouço teórico sobre as TDIC e suas relações com a formação do professor. Em seguida, passo a descrição do percurso metodológico desenvolvido para esta pesquisa. Posteriormente, trago a análise dos dados a partir da percepção de dois alunos de Letras-Inglês selecionados para a pesquisa. Por fim, teço algumas considerações sobre os desdobramentos da pesquisa.

\section{As tecnologias digitais na formação do professor}

As mudanças da sociedade na era digital levam os alunos a estar cada vez mais interligados e (inter)conectados com as TDIC, razão pela qual o papel do professor passa a ser proativo, dinâmico, desafiador, e por que não, motivador, nos cotidianos escolar e acadêmico. Pensar nas TDIC nesses contextos é possibilitar os seus potenciais usos pedagógicos como instrumentos comunicativos para o ensino e a aprendizagem, e maior investimento na formação de professores, seja pré-serviço, seja continuada ${ }^{3}$.

Afinal, como bem destaca Bates (2016), o simples uso das TDIC, por si mesmo, nos contextos educacionais, não implica uma mudança pedagógica pontual, caso não sejam, ao mesmo tempo, apresentadas propostas metodológicas e instrumentos pedagógicos adequados. Portanto, usar as TDIC ou mudá-las, alternadamente, e associá-las ao novo, não

\footnotetext{
${ }^{3}$ O Comitê Gestor da Internet no Brasil (2016) explicita ausência de oferta de cursos de formação aos docentes para o uso das TDIC na maioria das escolas brasileiras. Segundo esse Comitê, no caso em que os cursos são ofertados, os professores alegam não poder participar, seja por falta de tempo, em virtude da grande quantidade de aulas ministradas, seja pelo fato dos cursos serem realizados fora do horário de trabalho.
} 
se constitui em transformação, em avanço e em inovação, caso a prática pedagógica permaneça inalterada, conservadora e tradicional.

Bernabé (2012) enfatiza que não se pode conhecer e dominar uma variedade de interfaces digitais novas. Isso porque elas são criadas, desenvolvidas e disponibilizadas a um ritmo cada vez mais acelerado, tornando-se obsoletas rapidamente, também, a cada momento sócio-histórico e cultural, o que faz professores serem sempre eternos aprendizes dessas tecnologias.

Nessa direção, Echeverría (2015) pontua que as TDIC se tornam pouco duradouras, pois seus usos também mudam, o que exige a aprendizagem de novas competências. Não obstante, o uso reflexivo e a inserção nas diferentes disciplinas dos currículos escolares e acadêmicos podem promover difusão significativa e adaptável das TDIC a serviço da educação. Dessa forma, corroboro as ideias de Costa (2013) e compreendo as TDIC como vetores nucleares em cursos de formação de professores, com a necessidade de disciplinas acadêmicas curriculares específicas, para essa formação.

A escola precisa acompanhar o fluxo constante da informação e as diferentes maneiras de comunicação na Sociedade da Informação, em que as TDIC podem ser usadas e incorporadas na práxis social (BRAGA, 2013; PÉREZ-GÓMEZ, 2015). Assim como Ribeiro (2016, p. 135), também acredito que "a escola tem de estar atenta e aberta às mudanças que a inserção da sociedade no mundo digital exige para a socialização das novas gerações."

Para que essas mudanças, na sala de aula, sejam coerentes, significativas e possam, de fato, tornar as escolas verdadeiras agências interdisciplinares para o uso consciente, funcional e pedagógico das TDIC, Braga e Vóvio (2015) ponderam que o currículo, e aqui acrescento, também, o projeto político-pedagógico da escola ou da universidade, não sejam engessados e tradicionais. Dessa forma, faço também minhas as palavras de Almeida et al. (2017) ao pontuarem que

\begin{abstract}
a disseminação do uso das TDIC, o vertiginoso avanço da ciência e as transformações sociais fazem com que o referencial sobre currículo assuma novas características e se apresente com uma multiplicidade de referências e orientações teóricas e metodológicas. Surgem, assim, as propostas curriculares multi, inter $e$ transdiciplinares, que permitem compreender e tratar do currículo contextualizado e multirreferencial, que se concretiza na prática social pedagógica e cultural ao incorporar os elementos do cotidiano trazidos pelas experiências de professores, professoras, alunos e alunas nas distintas redes de interação das quais participam, desenvolvem e aprendem. (ALMEIDA et al., 2017, p. 393, grifos meus).
\end{abstract}

Saliento, assim, a importância da integração da cultura digital no ambiente de sala de aula no contexto brasileiro, em que os alunos poderão se apropriar, pedagógica e conscientemente, das mídias digitais e das tecnologias (IANNONE; ALMEIDA; VALENTE, 2016; PISCHETOLA, 2016; entre outros). Em outras palavras, é trazer e integrar à sala de aula o que já está legitimado fora dela, a cultura mediada pela tecnologia e todas as suas potencialidades. 
Assim sendo, compartilho a visão de Buckingham (2010, p. 42) quando afirma que "se as escolas de certa forma não foram atingidas pelo advento da tecnologia digital, o mesmo não pode ser dito da vida das crianças quando estão fora da escola." Complementando a visão do autor, acrescento também os jovens e os adultos.

Buckingham (2010) enfatiza também que a escola não pode ignorar a relação que as tecnologias e as mídias digitais passaram a ter na vida da maioria das pessoas e seu papel é mais que fundamental para ampliar o acesso à cultura digital, evitando, assim, um hiato entre a cultura oferecida pela escola e a cultura digital vivenciada fora do contexto extraescolar, tanto pelas crianças e pelos jovens, como pelos adultos, conhecida como "cultura tecnopopular" (BUCKINGHAM, 2010, p. 43). Em outras palavras, segundo o autor, trata-se de uma tecnologia que "se tornou do domínio da cultura popular." (BUCKINGHAM, 2010, p. 39).

É importante destacar que o Comitê Gestor da Internet no Brasil (2016, p. 97) reconhece que os formadores dos futuros docentes nos cursos de licenciatura, por exemplo, das universidades e faculdades, "precisarão de apoio para que preparem adequadamente os novos educadores das escolas públicas e privadas do país" para se adequarem "à realidade das escolas já informatizadas, em que seus alunos passarão a atuar profissionalmente, ou estejam preparados para a modernização tecnológica daqueles que ainda não dispõe da infraestrutura."

Assim sendo, considero que os Cursos de graduação em Letras precisam, portanto, oferecer esse tipo de formação para que esses profissionais, em formação inicial, possam desempenhar funções e desenvolver ações conscientes em seus futuros contextos de ensino e de aprendizagem, mediadas pela presença das tecnologias digitais.

Faz-se necessário, então, conforme salienta Pischetola (2016), a introdução, apropriação, integração e interpretação dos domínios funcionais, informacionais, técnicos e operacionais das TDIC nos cursos de formação. Ora, nessa ótica, pensa-se na temporalidade e no processo espiral (ALMEIDA; VALENTE, 2011) dos cursos de formação de professor, pois "é uma necessidade que a nova cultura e a nova sociedade exigem" (KENSKI, 2013, p. 91).

Para Schön (2000), as disciplinas acadêmicas, para formar professores, não deveriam ser enquadradas em um modelo normativo, com a apresentação de uma ciência básica, para depois aplicá-la e, por último, um espaço para um estágio no qual o futuro professor aplicaria os conhecimentos adquiridos ao longo do curso. Torna-se, assim, essencial, aos cursos de formação retomarem o papel do professor, considerando-o um agente proativo, questionador e reflexivo, que atuará em um contexto educacional complexo, dinâmico, não-ideal e mutável, pois "ser professor implica saber quem sou, as razões pelas quais faço o que faço" (ALARCÃO, 2013 , p. 177). O que pode, assim, levar esse profissional a se tornar consciente de seu papel nos contextos sociais, políticos, culturais, linguísticos e institucionais (GARCÍA, 1995; LIBÂNEO, 2012). Em outras palavras, trazendo novamente Schön (1983) para a discussão, vejo a necessidade de o professor sempre reestruturar sua prática na tentativa de saber analisar e lidar com as ações sob diferentes enfoques, teorizar os seus cotidianos de sala de aula, para, 
assim, organizar sua prática pedagógica e criar mudanças necessárias em seu contexto de ensino.

Nesse prisma, de acordo com a visão de Nóvoa (2014, p. 35), a formação de professores precisa perpassar "os discursos de superfície" para a produção de novos conhecimentos. Nessa formação, docentes deveriam estar inclinados ao pensamento prático, a aprender fazendo e refletindo na e sobre a ação (GÓMEZ, 1995; SCHÖN, 2000), refazendo constantemente sua práxis (FREIRE, 1968/2014). Em resumo, como ressalta Sacristán (2014), a própria prática pode dar origem ao saber regulador da mesma.

Revozeando Almeida e Valente (2011), os cursos de formação de professores voltamse, na maioria das vezes, ou para os aspectos tecnológicos ou para os aspectos pedagógicos. Segundo esses autores, o primeiro aspecto parte do pressuposto do possível conhecimento que o professor já tem de como proceder com os conteúdos, as metodologias, os objetivos e os procedimentos em sala de aula. É um professor consciente sobre sua prática, que receberá conhecimentos técnicos para o uso das TDIC e adicionará às suas práticas. Dessa forma, saberá como adaptar as mudanças necessárias.

No segundo aspecto, os cursos focam apenas no modelo pedagógico, do como fazer, em que as TDIC são vistas como meras ferramentas da informação. Por isso, é importante (inter)relacionar e integrar na mediação tecnológico-digital do professor, os conhecimentos técnicos e pedagógicos, simultaneamente, nos cursos de formação, pois um complementa o aspecto do outro. Compreendo, assim, que não se espera que ao término do curso, ao conhecer determinadas interfaces, os professores sejam especialistas em tecnologias digitais, capacitados a aplicarem o que aprenderam em seus contextos de sala de aula (ALMEIDA; VALENTE, 2011, 2016; PORTO, 2013; MAYRINK; ALBUQUERQUE-COSTA, 2017).

Logo, penso em uma formação reflexiva em que as TDIC possam fazer sentido de criação, invenção, motivação e inovação (LEVY, 1993) para a prática docente, e não se constituírem em um complemento, um acessório, para as atividades de sala de aula. Como afirma Alves (2014), não basta oferecer a mesma metodologia, o mesmo procedimento e os mesmos objetivos, com roupagens novas ou as antigas camufladas. Fazem-se necessárias novas mudanças de ações e de pensamento reflexivo do professor, também.

\section{Considerações metodológicas}

O objetivo deste artigo é apresentar a percepção de dois alunos do curso de LetrasInglês acerca do uso das TDIC para a aprendizagem de língua inglesa. Nessa vertente, a pesquisa teve a seguinte pergunta norteadora: "Como o uso das TDIC se faz presente na aprendizagem sob a percepção de futuros professores de inglês?".

O presente artigo, assim, caracteriza-se como um estudo de caso (STAKE, 1995; YIN, 2015) qualitativo. Para ser mais preciso, Yin (2015) entende estudo de caso como uma 
abordagem qualitativa de natureza empírica que busca compreender um caso contemporâneo a partir de um ambiente ou de um contexto da vida real.

Ecoando o pensamento de Stake (1995), de que estudo de caso é uma pesquisa qualitativa complexa ${ }^{4}$, relacionada a um caso contemporâneo social da vida real, em um sistema delimitado pelo tempo (que pode ser longo ou curto) e lugar, em que os participantes da pesquisa vivenciam o caso que está sendo estudado. Por essa razão, para esse autor, o estudo de caso é a escolha do objeto a ser estudado, holística, e significativamente, em seu contexto particular e natural, de maneira completa e profunda, tornando, assim, de acordo com André (2013), o estudo de caso mais concreto e mais contextualizado.

Para a realização deste artigo, os dados foram gerados a partir da disciplina curricular acadêmica "Tecnologias no ensino/aprendizagem de línguas estrangeiras", com carga horária de 68 h/a, da Faculdade de Letras Estrangeiras Modernas (FALEM) da Universidade Federal do Pará (UFPA). Um dos propósitos centrais dessa disciplina era provocar discussões, pesquisas e ações para o uso reflexivo das TDIC na formação inicial do professor de Letras-Inglês. As aulas aconteciam duas vezes por semana no turno noturno. Ressalta-se que essa disciplina sempre é ofertada aos alunos da FALEM no segundo semestre de cada ano letivo.

Isso posto, apresento os dados de dois alunos ${ }^{5}$ do curso de Letras-Inglês da FALEM, cujos nomes fictícios atribuídos por eles foram Lúkan e Tom, respectivamente. O primeiro participante tinha 23 anos e cursou toda a Educação Básica em escola pública. Concluiu o Ensino Médio em 2010 e, no ano seguinte, ingressou na universidade. No momento da geração dos dados, era bolsista, desde janeiro de 2012, no Laboratório de Informática (Lablnf) da (FALEM) durante o período matutino. Até aquele momento, não havia tido experiência com o magistério. Em relação às expectativas para com a disciplina curricular, esperava aprender novas formas de ensino com o uso das tecnologias digitais. Segundo Lúkan, os alunos vivem na era digital e, como futuro professor de inglês, precisava se adaptar e buscar formas de utilizar as TDIC a favor do ensino e da aprendizagem.

Já o segundo participante tinha 27 anos e havia cursado a Educação Básica completa em escola pública. Concluiu o Ensino Médio em 2003, ingressando no curso de Letras-Inglês, em 2011. Na época da geração dos dados, era professor de inglês do nono ano do Ensino Fundamental II em uma escola particular de Belém, onde trabalhava por um ano. Também atuava como professor-bolsista de inglês nos cursos de idiomas da UFPA, chamados Cursos Livres de Línguas Estrangeiras (CLLE), sediados na Faculdade de Letras Estrangeiras Modernas (FALEM). Estava em seu primeiro semestre e lecionava para duas turmas de primeiro nível. A

\footnotetext{
${ }^{4}$ Com relação a esse termo, trago as palavras literais do autor com relação ao estudo de caso: "Case study is the study of the particularity and complexity of a single case, coming to understand its activity within important circumstances" (STAKE, 1995, p. xi). "O estudo de caso é o estudo da particularidade e da complexidade de um caso único para compreender sua atividade considerando circunstâncias importantes." (STAKE, 1995, p. xi, tradução minha).

${ }^{5}$ Dezoito alunos cursaram a disciplina "Tecnologias no ensino/aprendizagem de línguas estrangeiras" à época da geração dos dados, porém, somente quatro alunos participaram efetivamente da pesquisa como todo. Por motivo de espaço neste artigo, apresento a percepção de apenas dois desses alunos.
} 
expectativa inicial de Tom em relação à disciplina era conhecer novas ferramentas digitais e saber como utilizá-las em sala de aula, além de trocar experiências com os colegas de turma e com o professor sobre o uso dessas ferramentas em prol da aprendizagem. Também esperava que a disciplina fosse bastante enriquecedora para seu currículo.

O processo de geração dos dados implicou em instrumentos característicos da pesquisa qualitativa, a saber: dois questionários, uma entrevista e relatos reflexivos. 0 primeiro questionário foi aplicado no meio do semestre em sala de aula e teve como objetivo obter informações sobre a familiaridade dos participantes com algumas interfaces tecnológicas digitais estudadas em sala de aula, a possibilidade de serem usadas em suas futuras práticas pedagógicas e o grau de dificuldade para compreendê-las. O segundo questionário foi aplicado no último dia de aula e teve por objetivos obter informações sobre o grau de dificuldade e as preferências dos participantes em relação às TDIC estudadas ao longo do semestre, a motivação para usá-las, as facilidades e as dificuldades com o uso das TDIC em sala de aula como futuro professor de inglês e a confirmação ou não das expectativas dos participantes em relação à disciplina curricular acadêmica.

A entrevista foi gravada em áudio em uma sala de aula da FALEM para esclarecimentos de alguma informação mencionada nos questionários e nos relatos reflexivos dos alunos. Os relatos reflexivos, por sua vez, tinham como objetivo apresentar as reflexões dos alunos, ao longo do semestre, para o uso das TDIC em suas formações como futuro professor de inglês.

A seguir, apresento e discuto a análise das percepções dos participantes em relação ao uso das TDIC na aprendizagem de língua inglesa, foco desta pesquisa.

\section{Apresentação e discussão dos resultados}

Nesta seção, procuro analisar os excertos da fala e as inferências dos dois alunos do Curso de Letras-inglês, aqui triangulados, sob o ponto de vista da fundamentação teórica e por meio dos três instrumentos de geração dos dados, que contribuíram para responder a minha pergunta da pesquisa mencionada anteriormente.

\section{A percepção de Lukan}

Lukan aponta que as tecnologias podem ser interfaces digitais atraentes para a aprendizagem de inglês dos alunos, motivando-os cada vez mais em suas atividades escolares. O excerto a seguir explana essa observação: 
Transcrição 1: questionário intermediário

Lukan: As tecnologias nos ajudarão a planejar aulas mais interativas e atrativas ${ }^{6}$ aos alunos para aprenderem inglês, pois se sentirão mais motivados no trabalho com a língua em sala de aula.

É possível perceber que Lukan possui uma visão motivadora para o uso das tecnologias com os alunos no contexto escolar. Segundo ele, as aulas bem planejadas com as TDIC podem contribuir para a interação e a inclinação dos alunos para a aprendizagem de inglês. As ponderações de Lukan parecem fazer sentido quando percebe a necessidade de olhar para o planejamento da aula para se chegar ao aluno, ou seja, aulas mais interativas e atrativas são sinônimas de alunos mais motivados, em sua opinião.

Possivelmente, a interatividade proporcionada pelas TDIC leve o aluno-professor a pensar dessa maneira, pois os alunos usam interfaces digitais que podem ser interativas e atraentes. Nesse sentido, corroboro as ideias de Ribeiro (2016, p. 161) ao reforçar que "a escola tem de estar atenta e aberta às mudanças que a inserção da sociedade no mundo digital exige para a socialização das novas gerações".

Lukan ainda destaca, na entrevista e em seu relato reflexivo, o uso do computador e do celular como interfaces digitais-pedagógicas para o ensino e a aprendizagem de inglês, pois, segundo ele, são muito familiares aos alunos para atividades de entretenimento. $\mathrm{Na}$ perspectiva de Lukan, a familiaridade com as interfaces aqui mencionadas pode facilitar seus usos para a realização de atividades com propósitos voltados ao ensino. Os excertos a seguir ilustram seu ponto de vista:

\section{Transcrição 2: entrevista}

Marcus: Na sua opinião, como futuro professor, que facilidades você aponta para o uso dos recursos tecnológicos?

Lukan: Os alunos utilizam muito o computador, o telefone, né? Então, se puder trazer isso para ensinar inglês ao aluno, vai ser bom.

Marcus: Bom em que sentido?

Lukan: Porque normalmente a gente proíbe, "não, não pode utilizar o computador em sala ou o tablet ou mesmo o celular". Então fazendo alguma atividade com a língua (inglesa) relacionada a isso eles vão ficar mais livres.

Marcus: Livres para quê?

Lukan: Eles estão mais acostumados a utilizar esses aparelhos no dia a dia [...] que eles são em certo ponto viciados nessa tecnologia. Então, tirar vantagem disso [...] para ensinar inglês. Acho que daria um upgrade na aula.

\section{Transcrição 3: relato reflexivo}

Lukan: A tecnologia é importante. Nesse caso, seria também importante usar com propósito pedagógico [...] trazer para sala de aula e fazer o aluno aprender com ela. No caso [...] utilizar o computador para fazer pesquisas, trabalhos [...] para eles [os alunos] verem que podem utilizar o computador para diversão, mas também para

\footnotetext{
${ }^{6}$ Decidi destacar em negrito alguns excertos dos alunos-professores com o objetivo de ressaltar informações relevantes para que possam me ajudar a analisar os resultados deste artigo.
} 
estudar e aprender inglês [...]. Então, eles aprenderiam dessa forma mais inovadora, diferente, na minha opinião.

É relevante salientar que Lukan revela uma conscientização de uso das TDIC para fins pedagógicos, ou seja, inserir no contexto escolar dos alunos o que é familiar fora dele para aprenderem inglês. Essa atitude de Lukan remete a sua preocupação com o ensino de inglês, inter-relacionando-o com as facilidades de uso que as tecnologias podem ocasionar.

O importante, segundo Lukan, não é mais proibir o uso das tecnologias (computador, tablet e celular) entre os alunos, mas agregá-las e tomá-las aliadas para o ensino da língua inglesa, o que pode se tornar um aspecto mais que positivo. Como bem salientam Bates (2016), o Comitê Gestor da Internet no Brasil $(2014,2016)$ e Fava $(2014,2016)$, as TDIC são interfaces catalisadoras para práticas didático-pedagógicas que podem se tornar motivadoras e transformadoras no processo de ensino-aprendizagem.

Apesar de Lukan mencionar o uso do celular para a aprendizagem de inglês, ele possivelmente ainda não tem conhecimento da legislação brasileira que proíbe o uso desse aparelho, mesmo para fins pedagógicos, na maioria das escolas públicas brasileiras ${ }^{7}$. Não obstante, não vejo esse fator como um entrave, pois ele certamente terá ciência da lei ao exercer a profissão.

É mister ressaltar que Lukan tem conhecimento amplo sobre várias interfaces tecnológicas, o que não prejudicaria seu trabalho com os alunos, podendo usar, inclusive, o computador, como mencionado por ele, para realizar pesquisas para o ensino e a aprendizagem de inglês. Em linhas gerais, Lukan parece entender que as TDIC se tornam relevantes para ensinar e aprender essa língua estrangeira, além de ser uma forma de inovação no contexto de sala de aula.

Interessante observar no excerto número três que Lukan associa a inserção das tecnologias a uma forma de inovação ao contexto escolar. Fica evidenciado em sua fala que o uso da tecnologia, por si mesma, já significa mudanças significativas na aprendizagem de língua inglesa. Essa constatação se justifica pelo fato de as tecnologias provocarem transformações generalizadas e profundas na vida das pessoas, seja no campo profissional, social e acadêmico, seja no âmbito cultural, econômico e de entretenimento.

Compreendo a visão de Lukan a esse respeito, porém entendo que as tecnologias usadas com propósitos inovadores no ensino e na aprendizagem de inglês precisam fazer a diferença, provocar uma mudança qualitativa nas escolas, e também incluo as universidades. Assim sendo, parafraseando o pensamento de Gilleran (2006), vejo que a simples presença das TDIC nas salas de aula não significa, por si mesma, uma mudança pedagógica, se, ao mesmo tempo, não forem introduzidos conhecimentos e interfaces digitais pedagógicas adequados.

\footnotetext{
${ }^{7}$ O Estado de São Paulo, a partir da Lei no 16.567, aprovada no dia 06 de outubro de 2017, autoriza o uso do telefone celular em sala de aula, desde que seja para fins pedagógicos.
} 
Diante do que foi discutido, os excertos das falas de Lukan levam-me a inferir que os benefícios de uso das TDIC para a aprendizagem do aluno são:

- planejamento de aulas mais interativas e atrativas;

- motivação para o trabalho com a língua inglesa;

- utilização do computador e do celular;

- atividades com o computador e com o celular;

- familiaridade com computadores e celulares e

- uso com propósito pedagógico para aprender inglês.

Lukan, assim, mostra-se consciente acerca das potencialidades de uso das TDIC no contexto educacional da contemporaneidade, pois, para o participante da pesquisa, o seu uso está mais que sacramentado fora dele. $\mathrm{O}$ aluno vê facilidades em práticas pedagógicas integrando interfaces das TDIC, pois acredita, e comungo com sua postura, que as tecnologias podem ajudar o aluno da escola e da universidade a aprender inglês de maneira participativa, interativa e dinamicamente.

\section{A percepção de Tom}

Tom menciona as tecnologias como forma de promover a interação e a curiosidade entre os alunos, além de torná-los envolvidos na aprendizagem da língua inglesa. Os excertos a seguir elucidam melhor suas falas:

\footnotetext{
Transcrição 4: questionário intermediário

Tom: As tecnologias podem promover uma maior interação entre os alunos fazendo que os mesmos estejam engajados e interessados para aprender inglês. As tecnologias, também, podem aguçar a curiosidade dos alunos, tornando-os autônomos em sua aprendizagem.
}

Transcrição 5: questionário final

Tom: As tecnologias chamam a atenção dos alunos para aprender inglês, porque eles sabem usá-las muito bem para se divertirem. Assim, o aluno pode ficar mais motivado em sala de aula para aprender a língua.

A fala de Tom nos excertos mencionados anteriormente parece apontar as tecnologias digitais da informação e comunicação como uma maneira de facilitar a aprendizagem de inglês, pois se tornam atraentes para a aprendizagem dos alunos. Posso observar nesses excertos de Tom que as tecnologias exercem papel relevante na educação, com contribuições que podem levar os alunos a aulas interessantes e motivadoras. Assim sendo, compartilho com o Comitê Gestor da Internet no Brasil (2016) a noção de que a sala de aula/escola pode 
ser um espaço de fomento para a inovação, a motivação e de apropriação interativa e criativa das (e com as) TDIC, gerando ambientes para se refletir sobre o processo de ensino e de aprendizagem.

As afirmações de Tom também me levam a pensar o caráter de curiosidade, mencionado por ele, que as tecnologias podem despertar nos alunos. Esse aspecto possivelmente possa estar relacionado à facilidade de acesso à informação que o aluno possui por meio de uso do computador (ou do celular) e da Internet, tornando-o curioso para pesquisar e para aprender sobre interfaces digitais de seu interesse. Não obstante, compreendo que esse acesso à informação parece ser realizado com poucas críticas e poucas reflexões por parte dos alunos.

Nessa direção, saliento a importância de integração das tecnologias para fins educacionais pelo professor como forma de estimular o pensamento crítico, fomentar a autonomia do aluno e as reais potencialidades trazidas pelas tecnologias e mídias digitais para o ensino e a aprendizagem da língua inglesa. Essa forma consciente de introdução das TDIC no currículo e nos contextos escolar e acadêmico pode proporcionar aos alunos uma maior curiosidade para aprender a língua-alvo, pois, assim, a escola estaria promovendo maneiras alternativas de ensinar e de aprender por meio do uso dessas tecnologias.

Sendo assim, corroboro as afirmações de Gil e Hernández-Hernández (2016) ao tratarem a respeito da aprendizagem baseada nas tecnologias web 2.0:

\footnotetext{
a sala de aula - ou o espaço que seja - do século XXI enfrenta a necessidade de mudar e reinventar a si mesma em termos de currículo (o que é necessário aprender) e de pedagogia (como contribuir para que essa aprendizagem seja eficaz, transferível e sustentável e para que não seja esquecida após os exames). (GIL; HERNÁNDEZHERNÁNDEZ, 2016, p. 12).
}

Em adição ao pensamento de Gil e Hernández-Hernández (2016), observo que a curiosidade despertada no aluno também pode estar inter-relacionada à necessidade de interação com o outro, caso se leve em consideração que as pessoas na era digital estão conectadas em rede. Assim sendo, pensar nas tecnologias como forma de interação é pensar nas "redes humanas de comunicação interpessoal" (VEEN; VRAKKING, 2009, p. 40) ou nas redes sociais para ajudar o usuário/aluno/aprendiz, quando necessário, para obter informações sobre algum assunto desconhecido. Talvez, por essa razão, Tom associe a interação das tecnologias com o engajamento e o interesse dos alunos para aprender inglês. Uma forma de todos se ajudarem quando precisarem um do outro e se sentirem motivados para buscar a informação desejada para algo que desconhecem.

Penso que, ao mencionar o caráter atrativo das tecnologias, Tom, como usuário, esteja pensando no caráter dinâmico, potencial e evolutivo que essas tecnologias podem promover para o aluno no contexto de sala de aula para aprender inglês. Caminhando nessa direção, as 
tecnologias podem fomentar o interesse dos alunos para aprender a língua-alvo, possivelmente, por conhecerem interfaces digitais que são usadas por eles em seus cotidianos para se entreterem, fato esse mencionado também por Lukan.

Tom menciona a autonomia dos alunos a partir do uso das tecnologias. Apesar deste artigo não ter o foco central nesse tema, compreendo sua posição. Especificamente no âmbito do ensino de inglês com a integração das TDIC, parto consequentemente do pressuposto que a educação não pode mais ser vista como um "ato de depositar, de transferir, de transmitir valores e conhecimentos" (FREIRE 1968/2014, p. 82).

As TDIC podem ajudar os alunos a tomar consciência para ter um desempenho satisfatório na escola e buscar o conhecimento por conta própria, assim como fazem em suas atividades no cotidiano. Em outras palavras, as tecnologias tornam-se elos de construção da informação e de mediação para o processo de ensino e de aprendizagem, pois o acesso às interfaces digitais nos dias de hoje pode facilitar esse processo, adequando-o às necessidades e aos ritmos de aprendizagem de cada aluno e tornando, também, o espaço e o tempo menos rígidos para o ensinar e para o aprender.

Vejo nesse contexto um aluno ativo e participativo, e por que não falar em um aluno curioso para aprender. Corroborando essas ideias, Martí (2013) reflete sobre a configuração da sociedade atual ocasionada pelas tecnologias digitais, em que o aluno/usuário/aprendiz pode ter um papel ativo na busca da informação para gerar o conhecimento, exigindo-se diferentes maneiras de aprender e de construir o conhecimento.

Dentro da perspectiva exposta, pode-se compreender que, na percepção de Tom, a aprendizagem com o uso das TDIC contribui para:

- promover interação;

- engajar-se para aprender inglês;

- aguçar a curiosidade e

- fomentar a autonomia.

É visível a necessidade trazida pelas tecnologias no cotidiano, demonstrando a relação cada vez mais estreita e dependente do homem da contemporaneidade com o computador, com a Internet e com outras interfaces digitais. Então, corroboro as afirmações de Gilleran (2006, p. 86) ao considerar que "não se pode negar que, durante as últimas décadas, a revolução tecnológica vem tendo um impacto considerável e está mudando o cotidiano."

Por essa razão, compreendo a interação entre os alunos como parte do processo dialógico, como menciona Freire (1968/2014; 1996/2004), para a conscientização e para a aprendizagem de inglês por meio da integração de uso com as tecnologias. Essas podem fomentar práticas autônomas e desafiadoras para os alunos no contexto escolar, como salientou Tom em suas falas. 


\section{Considerações finais}

A sociedade atual vive processos de mudanças tecnológicas constantes, o que leva os sujeitos (alunos, professores, gestores e pedagogos) que atuam na escola a mudarem o seu fazer, como forma de atender às novas demandas da educação, por exemplo, e aos novos papéis exigidos pelo mundo globalizado. É nesse sentido, possivelmente, os benefícios apontados por Lukan e Tom para o uso das tecnologias digitais da informação e comunicação no processo de ensino e de aprendizagem de inglês. Neste artigo, apresentei a percepção desses dois alunos do Curso de Letras-Inglês em relação à aprendizagem ao uso educacional das TDIC.

Como observado nos dados, Lukan apresenta-se favorável ao uso do computador e do celular para a realização de atividades em inglês, pelo fato de os alunos, e ele mesmo, estarem familiarizados com as interfaces digitais em seu cotidiano. $O$ aluno reconhece as potencialidades das TDIC em relação ao planejamento de aulas, que podem se tornar interativas e atrativas, motivando o aluno a estudar e a aprender inglês. Por sua vez, Tom pontua que as tecnologias digitais da informação e comunicação podem promover interação entre os alunos, o que pode proporcionar engajamento e autonomia na aprendizagem de inglês, além de aguçar suas curiosidades.

Diante das falas de Lukan e Tom, convenço-me, cada vez mais, de que a formação reflexiva, tecnológico-digital e pedagógica do professor de inglês deveria constituir uma prática sólida e necessária para mudanças imperativas em sua prática para o uso consciente das TDIC. Caminhando nessa direção, corroboro as ideias de Moita-Lopes (2003, p. 131) ao defender que "não se pode transformar o que não se entende."

De acordo com as falas dos dois alunos de Letras-Inglês deste artigo, posso inferir que as tecnologias representam um dos elementos no ensino de inglês que podem propiciar inovação, interação, motivação, novidade, planejamento, entre outros fatores, na aprendizagem da língua-alvo, já que se vive em uma era digital. Nesse sentido, considerando os posicionamentos dos alunos da pesquisa, posso deduzir que a escola (incluo também a universidade), precisa acompanhar as mudanças proporcionadas pelas TDIC.

Dessa forma, sou levado a admitir, ao lado de Almeida e Valente (2011, 2016), Bates (2016) e Pischetola (2016), que as TDIC são apenas um componente dentro de qualquer ambiente de ensino e de aprendizagem eficaz, precisando ser equilibradas e integradas, reflexivamente, com os demais componentes educacionais, como, por exemplo, a formação do professor, escolhas de metodologias e de abordagens comunicativas, apoio e incentivo dos órgãos governamentais, entre outros fatores.

O ensino precisa ser desafiador para o aluno, o que leva o professor a se especializar e a compreender cada vez mais as especificidades das interfaces tecnológicas digitais, para adaptá-las ao seu fazer pedagógico. Dessa forma, é preciso lembrar que a formação docente, 
principalmente para o aluno do curso de Letras, se torna necessária, para que mudanças concretas possam acontecer na tentativa de se repensar novas futuras ações do professor em seus futuros contextos de ensino e de aprendizagem de inglês mediados pelo uso das tecnologias digitais da informação e comunicação, com currículos menos rígidos e menos prescritivos. O currículo na formação de professores deveria ser pensado como mediador potencial às diversidades e às necessidades dos alunos no processo de ensino e de aprendizagem.

\section{Referências}

ALARCÃO, I. Ser professor reflexivo. In: ALARCÃO, I. (org.). Formação reflexiva de professores: estratégias de supervisão. Porto: Porto Editora, 2013. p. 171-189.

ALMEIDA, M. E. B. et al. O currículo na cultura digital e a integração currículo e tecnologias. In: CERNY, R. Z. et al. (orgs.). Formação de Educadores na Cultura Digital. Florianópolis: UFSC/CED/NUP, 2017. Disponível em: http://nup.ced.ufsc.br/e-books. Acesso em: 9 fev. 2020.

ALMEIDA, M. E. B.; VALENTE, J. A. Tecnologias e currículo: trajetórias convergentes ou divergentes? São Paulo: Paulus, 2011.

ALMEIDA, M. E. B.; VALENTE, J. A. Políticas de tecnologia na educação brasileira: histórico, lições aprendidas e recomendações. São Paulo: Centro de Inovação para a Educação Brasileira - CIEB Estudos, 2016. Disponível em: http://cieb.net.br/wp-content/uploads/2019/04/CIEBEstudos-4-Politicas-de-Tecnologia-na-Educacao-Brasileira-v.-22dez2016.pdf Acesso em 28 de mar. 2020.

ALVES, A. C. T. P. Web currículo - anúncio de possível superação de alguns entraves encontrados na educação no início do século XXI. In: ALMEIDA, M. E. B.; ALVES, D. R. M.; LEMOS, S. D. V. (orgs.). Web currículo: aprendizagem, pesquisa e conhecimento com o uso de tecnologias digitais. Rio de Janeiro: Letra Capital, 2014. p. 57-70.

ANDRÉ, M. E. D. A. O que é um estudo de caso qualitativo em Educação? Revista da FAEEBA Educação e Contemporaneidade. Salvador, v. 22, n. 40, p. 95-103, jul./dez. 2013. https://doi.org/10.21879/faeeba2358-0194.v22.n40.753

BATES, A. W. T. Educar na era digital: design, ensino e aprendizagem. São Paulo: Artesanato Educacional, 2016.

BERNABÉ, I. Os professores como aprendizes com as TICs. In: BARBA, C.; CAPELLA, S. (orgs.). Computadores em sala de aula: métodos e usos. Porto Alegre: Penso, 2012. p. 77-83.

BRAGA, D. B. Ambientes digitais: reflexões teóricas e práticas. São Paulo: Cortez, 2013.

BRAGA, D. B.; VÓVIO, C. L. Uso de tecnologia e participação em letramentos digitais em contextos de desigualdade. In: BRAGA, D. B. (org.). Tecnologias digitais da informação $e$ comunicação e participação social. São Paulo: Cortez, 2015. p. 33-67.

BUCKINGHAM, D. Cultura digital, educação midiática e o lugar da escolarização. Educação \& Realidade. Porto Alegre, v. 35, n. 3, p. 37-58, set./dez., 2010. 
COMITÊ GESTOR DA INTERNET NO BRASIL. Pesquisa sobre o uso das tecnologias de informação e comunicação nas escolas: TIC Educação 2013. São Paulo: CGI.br, 2014.

COMITÊ GESTOR DA INTERNET NO BRASIL. Educação e tecnologias no Brasil: um estudo de caso longitudinal sobre o uso das tecnologias de informação e comunicação em 12 escolas públicas. São Paulo: CGI.br, 2016.

COSTA, F. A. O potencial transformador das TIC e a formação de professores e educadores. In: ALMEIDA, M. E. B.; DIAS, P.; SILVA, B. D. (orgs.). O cenário de inovação para a educação na sociedade digital. São Paulo: Edições Loyola, 2013. p. 47-74.

ECHEVERRÍA, J. A escola contínua e o trabalho no espaço-tempo eletrônico. In: JARAUTA, B.; IMBERNÓN, F. (Orgs.). Pensando no futuro da educação: uma nova escola para o século XXII. Porto Alegre: Penso, 2015. p. 38-50.

FAVA, R. Educação 3:0 - aplicando o PDCA nas instituições de ensino. São Paulo: Saraiva, 2014.

FAVA, R. Educação para o século 21: a era do indivíduo digital. São Paulo: Saraiva, 2016.

FREIRE, P. Pedagogia da autonomia: saberes necessários à prática educativa. 30. ed. São Paulo: Paz \& Terra, 1996/2004.

FREIRE, P. Pedagogia do oprimido. São Paulo: Paz \& Terra, 1968/2014.

GARCÍA, C. M. A formação de professores: novas perspectivas baseadas na investigação sobre o pensamento do professor. In: NóVOA, A. (coord.). Os professores e a sua formação. Lisboa: Dom Quixote, 1995. p. 51-76.

GILLERAN, A. Práticas inovadoras em escolas europeias. In: SANCHO, J. M.; HERNÁNDEZ, F. (org.). Tecnologias para transformar a educação. Porto Alegre: Artmed, 2006. p. 85-109.

GÓMEZ, A. P. O pensamento prático do professor: a formação do professor como profissional reflexivo. In: NÓVOA, A. (coord.). Os professores e a sua formação. Lisboa: Dom Quixote, 1995. p. 93-114.

HERNÁNDEZ, F. (org.). Professores na incerteza: aprender a docência no mundo atual. Porto Alegre: Penso, 2016.

IANNONE, L. R.; ALMEIDA, M. E. B.; VALENTE, J. A. Pesquisa TIC Educação: da inclusão para a cultura digital. In: Pesquisa sobre o uso das tecnologias de informação e comunicação nas escolas brasileiras: TIC Educação 2015. São Paulo: Comitê Gestor da Internet no Brasil, 2016. p. 55-67.

IMBERNÓN, F. Qualidade do ensino e formação do professorado: uma mudança necessária. São Paulo: Cortez, 2016.

KENSKI, V. M. Tecnologias e tempo docente. Campinas: Papirus, 2013.

LEVY, P. As tecnologias da inteligência: o futuro do pensamento na era da informática. Rio de Janeiro: Editora 34, 1993.

LIBÂNEO, J. C.; OLIVEIRA, J. F.; TOSCHI, M. S. Educação escolar: políticas, estrutura e organização. $10^{\circ}$ ed. São Paulo: Cortez, 2012.

LIBERALI, F. C. Formação crítica de educadores: questões fundamentais. Campinas: Pontes, 2010. 
MARTÍ, E. A escola diante do desafio tecnológico. In: GÓMEZ-GRANELL, C.; VILA, I. (org.). A cidade como projeto educativo. Porto Alegre: Artmed, 2013. p. 129-152.

MAYRINK, M. F.; ALBUQUERQUE-COSTA, H. Ensino presencial e virtual em sintonia na formação em línguas estrangeiras. The ESPecialist: Descrição, Ensino e Aprendizagem. São Paulo. v. 38, n. 1, p. 1-14, jan.-jul. 2017. https://doi.org/10.23925/2318-7115.2017v38i1a10

MOITA LOPES, L. P. A nova ordem mundial, os parâmetros curriculares nacionais e o ensino de inglês no Brasil: a base intelectual para uma ação política. In: BARBARA, L.; RAMOS, R. C. G. (orgs.). Reflexão e ações no ensino-aprendizagem de línguas. Campinas: Mercado de Letras, 2003. p. 29-57.

NÓVOA, A. Formação de professores e profissão docente. In: NÓVOA, A. (coord.). Os professores e a sua formação. Lisboa: Dom Quixote, 1995. p. 15-33.

NÓVOA, A. Os professores e o "novo" espaço público da educação. In: TARDIF, M.; LESSARD, C. (orgs.). O ofício de professor: histórias, perspectivas e desafios internacionais. $6^{\circ}$ ed. Petrópolis: Vozes, 2014.

PÉREZ GÓMEZ, Á. I. P. Educação na era digital: a escola educativa. Porto Alegre: Penso, 2015. PISCHETOLA, M. Inclusão digital e educação: a nova cultura da sala de aula. Petrópolis: Vozes, 2016.

PORTO, T. M. E. As tecnologias estão na escola. E agora, o que fazer com elas? In: FANTIN, M.; RIVOLTELLA, P. C. (orgs.). Cultura digital e escola: pesquisa e formação de professores. Campinas: Papirus, 2013.

RAMOS, R. C. G. Um projeto que deu certo: reflexão sobre a ação. In: SILVA, K. A.; MASTRELLADE-ANDRADE, M.; PEREIRA FILHO, C. A. (orgs.). A formação de professores de línguas: políticas, projetos e parcerias. Campinas: Pontes, 2015. p. 171-188.

RIBEIRO, A. L. Jogos online no ensino-aprendizagem da leitura e da escrita. In: COSCARELLI, C. V. (org.). Tecnologias para aprender. São Paulo: Parábola, 2016. p. 159-174.

SACRISTÁN, J. G. Consciência e ação sobre a prática como libertação profissional dos professores. In: NÓVOA, A. (org.). Profissão professor. 2. ed. Porto: Editora Porto, 2014. p. 6392.

SCHÖN, D. A. The reflective practitioner: how professionals think in action. Nova York: Basic Books, 1983.

SCHÖN, D. A. Educando o profissional reflexivo: um novo design para o ensino e a aprendizagem. Reimpressão 2008. Porto Alegre: Artmed, 2000.

STAKE, R. E. The art of case study research. Londres: SAGE Publications, 1995.

VEEN, W.; VRAKKING, B. Homo zappiens: educando na era digital. Porto Alegre: Artmed, 2009.

YIN, R. K. Estudo de caso: planejamento e métodos. 5. ed. Porto Alegre: Bookman, 2015.

Recebido em: 29/09/2019. Aceito em: 20/03/2020. 